\title{
Efficacy and tolerability of switching to a dual therapy with darunavir/ritonavir plus raltegravir in HIV-infected patients with HIV-1 RNA $\leq \mathbf{5 0} \mathrm{cp} / \mathrm{mL}$
}

\author{
Giordano Madeddu1 ${ }^{1}\left[\right.$ Stefano Rusconi $^{2} \cdot$ Alessandro Cozzi-Lepri $^{3} \cdot$ Simona Di Giambenedetto $^{4} \cdot$ \\ Stefano Bonora ${ }^{5} \cdot$ Alessia Carbone $^{6} \cdot$ Andrea De Luca $^{7} \cdot$ Nicola Gianotti $^{6} \cdot$ Antonio Di Biagio $^{8} \cdot$ Andrea Antinori $^{9} \cdot$ \\ for the Icona Foundation Study Group
}

Received: 14 November 2016 / Accepted: 13 April 2017 / Published online: 5 May 2017

(C) Springer-Verlag Berlin Heidelberg 2017

\begin{abstract}
Background Nucleos(t)ide reverse transcriptase inhibitors (NRTI) toxicity may represent a threat for long-term success of combined antiretroviral therapy. Some studies have suggested a possible improvement of NRTI-related toxicity after switching to NRTI-sparing regimens.

Objectives We aimed to explore the efficacy and tolerability of switching to darunavir/ritonavir (DRV/r) plus
\end{abstract}

Giordano Madeddu

giordano@uniss.it

1 Department of Clinical and Experimental Medicine, Unit of Infectious Diseases, University of Sassari, Viale San Pietro 8, 07100 Sassari, Italy

2 Infectious Diseases Unit, DIBIC Luigi Sacco, University of Milan, Milan, Italy

3 Department of Infection and Population Health, Division of Population Health, Hampstead Campus, University College London, London, UK

4 Catholic University of the Sacred Heart, Milan, Unit of Infectious Diseases, Agostino Gemelli Polyclinic Foundation, Rome, Italy

5 Unit of Infectious Diseases, Department of Medical Sciences, University of Turin, Turin, Italy

6 Infectious Diseases Department, San Raffaele Scientific Institute, Università vita e salute, Milan, Italy

7 Division of Infectious Diseases, Department of Medical Biotechnologies, University of Siena and Siena University Hospital, Siena, Italy

8 Unit of Infectious Diseases, IRCCS San Martino HospitalIST, Genoa, Italy

9 Clinical Department, National Institute of Infectious Diseases 'Lazzaro Spallanzani', Rome, Italy raltegravir (RAL) while having a viral load (VL) $\leq 50$ cop$\mathrm{ies} / \mathrm{mL}$ in the clinical setting.

Study design Treatment-experienced HIV 1-infected patients enrolled in the ICONA Foundation Study cohort were included if they switched their current regimen to $\mathrm{DRV} / \mathrm{r}+\mathrm{RAL}$ with a HIV-RNA $\leq 50$ copies/mL. Different definitions of virological failure (VF) and treatment failure (TF) were employed. Kaplan-Meier curves and Cox regression models were performed to estimate time to event probability.

Results We included 72 HIV-infected patients, 22 (31\%) of these were female, 31 (43\%) men who have sex with men (MSM) amd 15 (21\%) had hepatitis co-infections. Median age was 44 (IQR: 35-50) years amd CD4 count was 389 (IQR 283-606) cells/mmc. Median follow-up time for TF was 24 (IQR 9-31) months. Twenty-five discontinuations occurred (60\% simplifications); only $2(8 \%)$ were toxicity-driven (lipid elevations). The probability of VF (confirmed VL >50 copies $/ \mathrm{mL}$ ) was estimated at 7\% [95\% confidence interval (CI) $1-13 \%$ ] by 12 and $9 \%(95 \% \mathrm{CI}$ $2-16 \%$ ) by 24 months. When considering TF, we found a probability of stop/intensification/single VL > 200 copies/ $\mathrm{mL}$ of $13 \%(95 \%$ CI $1-17 \%)$ and $22 \%$ (95\% CI $11-33 \%)$ by 12 and 24 months. Female gender (adjusted relative hazard, $\mathrm{ARH}=0.10 ; 95 \% \mathrm{CI} 0.01-0.74 ; p=0.024$ ) and older age $(\mathrm{AHR}=0.50$ per 10 years older; 95\% CI $0.25-0.99 ; p=0.045)$ were associated with a lower risk of TF. A previous PI failure was strongly associated with TF $(\mathrm{AHR}=52.6,95 \%$ CI 3.6-779; $p=0.004)$.

Conclusions DRV/r + RAL is a valuable NRTI-sparing option, especially in female and older patients, with a relatively low risk of VF and good tolerability after 2 years since start in an ART-experienced population. However, previous PI-failure should be a limiting factor for this strategy. 
Keywords Darunavir/ritonavir · Raltegravir - Efficacy · Tolerability $\cdot$ Antiretroviral therapy $\cdot$ NRTI-sparing regimen

\section{Background}

Nucleos(t)ide reverse transcriptase inhibitors (NRTI) toxicity may represent a threat for long-term success of combined antiretroviral therapy (cART) [1-3]. Some studies have suggested a possible improvement of NRTI-related toxicity after switching to NRTI-sparing or single NRTIincluding regimens [4-6]. In a recent study conducted in patients receiving a successful multidrug salvage regimen with at least two active drugs including a boosted protease inhibitor (PI), the withdrawal of NRTI was safe [7]. Two NRTI plus a third drug, a PI, an integrase inhibitor (INI) or non-nucleoside reverse transcriptase inhibitor (NNRTI) still represent the cornerstone for cART initiation in naïve patients, and the International and National treatment Guidelines do not recommended NRTI-sparing regimens in the first-line [8-11].

Although most studies were conducted in the scenario of antiretroviral-naïve patients, in clinical practice, this NRTIsparing regimen is being employed in different strategies (salvage, simplification, switching). Other studies suggest that the combination is indeed widely used, at least in Spain and Italy [7, 12-14]. A recent study by Calza et al. showed that in 82 virologically suppressed patients without history of PI failure the combination of RAL + DRV/r was capable of maintaining a virologic success in more than $92.7 \%$ of cases at 48 weeks with a significant improvement of lipid profile and reduction of tubular proteinuria [15].

\section{Objectives}

In this analysis, we aimed to investigate the risk of virological failure (VF), and tolerability of switching to DRV/r plus RAL while having a viral load (VL) $\leq 50$ copies $/ \mathrm{mL}$ in an unselected population from the real life setting.

\section{Study design}

Treatment experienced HIV-1-infected patients enrolled in the ICONA (Italian Cohort Naïve Antiretrovirals) Foundation Study cohort were included in this analysis if they switched their current regimen to DRV/r + RAL with an HIV-RNA $\leq 50$ copies/mL (baseline). No patient had previous exposure to integrase inhibitors. Virological failure (VF) was defined as a confirmed HIV-RNA >50 copies/ $\mathrm{mL}$ (two consecutive values). We also investigated the risk of treatment failure (TF) defined as single HIV-RNA $>200$ copies $/ \mathrm{mL}$, intensification or discontinuation of $\mathrm{DRV} / \mathrm{r}+\mathrm{RAL}$ for any reason. Glomerular filtration rate was estimated using the CKD-EPI formula [16]. A range of methods were used to measure HIV-RNA according to availability at the participating sites. The most frequent were Real time Abbot PCR $(n=10,13 \%)$, NASBA $(n=4$, $6 \%)$ and Roche $(n=3,4 \%)$.

We performed time to event estimates using KaplanMeier curves and Cox regression models. Covariates in the final model included the number of failures on regimens containing a PI, gender, mode of HIV transmission, HBV/ HCV co-infection, calendar year of switch, age, CD4 nadir count, CD4 count at cART initiation, viral load at cART initiation and duration of viral suppression $<50$ copies $/ \mathrm{mL}$.

\section{Results}

Seventy-two patients were included: 22 (31\%) female, 31 (43\%) MSM, 15 (21\%) had hepatitis co-infections (10 with HCV and 5 with HBV). Median baseline characteristics were age 44 [Interquartile range (IQR) 35-50] years, CD4 cell count was 389/mmc (IQR 283-606); HIV-RNA at initiation of cART was 4.22 (IQR $2.92,6.54) \log _{10}$ copies/mL and total median duration of HIV-RNA $\leq 50$ copies/ $\mathrm{mL} 5$ months (IQR 1-53). Time from initiation of previous ART was 3 (IQR 1-30) months and median time from first starting antiretrovirals to the switch to DRV/r + RAL was 10 months (IQR 1-109). Seventy-four (88.9\%) patients were receiving a boosted PI at baseline and 14 (19\%) patients previously failed virologically a PI-based cART before baseline. On average participants have been previously exposed to two lines of treatment (IQR 1-5), for 65\% the dual regimen was the 4th therapy started. Forty-eight of the 72 patients $(67 \%)$ were already receiving darunavir/r prior to switching to the dual regimen. Thirty-one (43\%) patients switched from a 2 NRTI-including triple cART, 35 (49\%) from a PI monotherapy, 3 (4\%) from a NRTI + PI/r regimen and $3(4 \%)$ from other NRTI-including regimens.

Median total cholesterol levels were 180 (IQR 155-224) $\mathrm{mg} / \mathrm{dl}$, HDL 45 (IQR 35-54) mg/dl and triglycerides 106 (IQR 75-156) mg/dl. Complete baseline patients characteristics are shown in Table 1. The median follow-up time for the composite endpoint was 24 (IQR 9-31) months. The median follow-up time by gender was 24.5 months (IQR 12-31) in males and 17.5 (5-33) in females. The proportion of people with at least 24 months of follow-up was $27 / 50$ (54\%) among males and 10/22 (45\%) among females.

Overall, we observed 30 discontinuation events of the dual regimen. However, regimen simplification in terms of pill burden was the most frequent cause of discontinuation and occurred in 15 out of 30 patients (50\%), 14 of whom 
Table 1 Baseline

characteristics of 72 patients

with HIV RNA $<50 \mathrm{cp} /$

$\mathrm{ml}$ switching to darunavir/

ritonavir + raltegravir

\begin{tabular}{|c|c|}
\hline Characteristics & Total $N=72$ \\
\hline \multicolumn{2}{|l|}{ Gender, $n(\%)$} \\
\hline Female & $22(30.6 \%)$ \\
\hline \multicolumn{2}{|l|}{ Mode of HIV Transmission, $n(\%)$} \\
\hline IDU & $8(11.1 \%)$ \\
\hline Homosexual contacts & $31(43.1 \%)$ \\
\hline Heterosexual contacts & $30(41.7 \%)$ \\
\hline Other/unknown & $3(4.2 \%)$ \\
\hline Hepatitis co-infection ${ }^{*}, n(\%)$ & $15(20.8 \%)$ \\
\hline Calendar year of starting dual RAL/DRV & $2012(2011,2013)$ \\
\hline Age, years & $44(35,50)$ \\
\hline CD4 count at starting dual RAL/DRV, cells/mmc & $389(283,606)$ \\
\hline ALT at starting dual RAL/DRV, UI/L & $20(17,28)$ \\
\hline AST at starting dual RAL/DRV, UI/L & $24(9,117)$ \\
\hline Viral load at initiation of cART, $\log 10$ copies $/ \mathrm{mL}$ & $4.22(2.92,6.54)$ \\
\hline Follow-up for composite outcome, months & $24(9,31)$ \\
\hline Time from ART initiation to start of dual RAL/DRV, months & $10(1,109)$ \\
\hline \multicolumn{2}{|l|}{ Type of cART in use prior to switch, $n(\%)$} \\
\hline $\mathrm{PI} / \mathrm{r}$ & $64(88.9 \%)$ \\
\hline Darunavir/r & $48(66.7 \%)$ \\
\hline Atazanavir/r & $10(13.9 \%)$ \\
\hline Lopinavir/r & $6(8.3 \%)$ \\
\hline NNRTI & $5(6.9 \%)$ \\
\hline Efavirenz & $2(2.8 \%)$ \\
\hline Nevirapine & $3(4.2 \%)$ \\
\hline Other & $3(4.2 \%)$ \\
\hline Previously virologically failed a PI & $14(19.4 \%)$ \\
\hline Time with VL $\leq 50$ before switch to RAL/DRV, months median (IQR) & $16(1,63)$ \\
\hline CD4 nadir, cells/mmc & $236(102,341)$ \\
\hline CD4 at time of starting cART, cells/mmc & $371(237,536)$ \\
\hline eGFR at starting dual RAL/DRV, $\mathrm{mL} / \mathrm{min} / 1.73 \mathrm{~m}^{2}$ & $92(70,109)$ \\
\hline Cholesterol at starting dual RAL/DRV, mg/dL & $180(155,224)$ \\
\hline $\mathrm{HDL}$ at starting dual RAL/DRV, mg/dL & $45(35,54)$ \\
\hline Triglycerides at starting dual RAL/DRV, mg/dL & $106(75,156)$ \\
\hline Time from initiation of previous cART, years & $1(1,29)$ \\
\hline
\end{tabular}

Data are expressed as median and interquartile range (IQR) or number (\%)

$R A L$ raltegravir, $D R V$ darunavir, $N R T I$ nucleoside reverse transcriptase inhibitors, NNRTI non-nucleoside reverse transcriptase inhibitors, $P I$ protease inhibitor, $e G F R$ estimated glomerular filtration rate (CKD-EPI formula), $H D L$ high-density lipoprotein, $c A R T$ combination antiretroviral therapy

*Hepatitis C or Hepatitis B co-infection discontinued RAL, whereas toxicity-driven interruption occurred only in $3(10 \%)$ cases (1 lipid elevation, 1 renal and 1 central nervous system toxicity). The remaining causes of discontinuations included patients' decision in $2(7 \%)$ and drugdrug interactions, compliance with guidelines, virological failure, immunological failure, regimen intensification, death, temporary stop (physician's decision) in $1(3 \%)$ case each. In $2(7 \%)$ patients the cause of discontinuation was unknown.

Table 2 shows the number of patients experiencing VF and TF and the Kaplan-Meier estimates by 12 and
24 months, respectively, for each of the adopted endpoints. The probability of VF defined as confirmed VL >50 copies/mL was $7 \%$ [95\% confidence interval (CI) $1-13 \%$ ] by 12 months and $9 \%$ (95\% CI 2-16\%) by 24 months. When considering the composite endpoint of $\mathrm{TF}$ we found a probability of stop/intensification and single value of $\mathrm{VL}$ $>200$ copies $/ \mathrm{mL}$ of $13 \%$ (95\% CI $1-17 \%)$ and $22 \%(95 \%$ CI $11-33 \%$ ) by 12 and 24 months, respectively.

Still considering the composite TF endpoint defined as stop/intensification and single value of VL >200 copies/ 
Table 2 Number of patients experiencing virological failure (VF) and treatment failure (TF) and the Kaplan-Meier estimates by 12 and 24 months

\begin{tabular}{|c|c|c|c|c|c|c|}
\hline \multirow[t]{2}{*}{ Endpoint } & \multicolumn{3}{|l|}{12 months } & \multicolumn{3}{|l|}{24 months } \\
\hline & No. events & Point estimate $(\%)$ & $95 \% \mathrm{CI}(\%)$ & No. events & Point estimate $(\%)$ & $95 \% \mathrm{CI}(\%)$ \\
\hline \multicolumn{7}{|l|}{ Pure virological failure (VF) } \\
\hline $\begin{array}{l}\text { Confirmed }^{\mathrm{a}} \text { VL }>50 \text { copies } / \mathrm{mL} \\
\text { Treatment failure }(\mathrm{TF})\end{array}$ & 5 & 7 & $1-13$ & 6 & 9 & $2-16$ \\
\hline Single VL >200 copies/mL or stop/intensification & 9 & 13 & $1-17$ & 13 & 22 & $11-33$ \\
\hline
\end{tabular}

${ }^{\text {a }}$ First of two consecutive VL values

$\mathrm{mL}$, from fitting a multivariable Cox regression analysis, female gender (adjusted relative hazard, ARH $=0.10 ; 95 \%$ CI $0.01,0.74, p=0.024)$ and older age (AHR $=0.50$ per 10 years older; $95 \%$ CI $0.25-0.99, p=0.045$ ) were associated with a lower risk of TF. Having previously experienced virological failure to a PI-based regimen was the strongest predictor of failure of the dual strategy (AHR $=52.6,95 \%$ CI 3.6-779, $p=0.004)$. In contrast, viral load at starting cART, CD4 cell nadir and hepatitis coinfections were not associated with increased risk of TF (Table 3).

Historical genotypes were available for 47/72 (65\%) patients. When looking at the virological endpoint of time to a single VL $>200$ copies (part of the composite outcome) those with major IAS PI resistance mutations $(2 / 5,40 \%)$ showed a higher risk of failure compared to those without $(8 / 34,19 \%)$ but the difference was not statistically significant (Chi square $p=0.28$ ). The univariate Hazard ratio (HR) for failure from fitting a univariable Cox regression model was 2.12 (95\% CI $0.80-5.66, p=0.13$ ) for those with PI resistance vs. no PI resistance detected.

When looking at the endpoint of confirmed VL $>50$ copies $/ \mathrm{ml}$ results were similar with patients with major PI resistance mutations $(2 / 5,40 \%)$ showing an increased risk of failure compared to those without $(6 / 42,14 \%, p=0.15)$.
Table 3 Relative Hazard of single VL $>200 \mathrm{cp} / \mathrm{mL}$ or stop/ intensification

\begin{tabular}{|c|c|c|c|c|}
\hline & \multicolumn{4}{|c|}{$\begin{array}{l}\text { Unadjusted and adjusted relative hazards of single VL }>200 \text { or stop/ } \\
\text { intensification }\end{array}$} \\
\hline & Unadjusted RH (95\% CI) & $p$ value & Adjusted* RH (95\% CI) & $p$ value \\
\hline \multicolumn{5}{|l|}{ Gender } \\
\hline Female vs. male & $0.31(0.11,0.89)$ & 0.029 & $0.10(0.01,0.74)$ & 0.024 \\
\hline \multicolumn{5}{|l|}{ Mode of HIV transmission } \\
\hline Homosexual contacts vs. IDU & $0.98(0.22,4.33)$ & 0.984 & $0.64(0.08,5.25)$ & 0.675 \\
\hline Heterosexual contacts vs. IDU & $0.51(0.11,2.41)$ & 0.395 & $0.52(0.05,5.51)$ & 0.584 \\
\hline \multicolumn{5}{|l|}{ Hepatitis co-infection ${ }^{*}$} \\
\hline Yes vs. No & $1.06(0.40,2.80)$ & 0.907 & $0.47(0.10,2.26)$ & 0.345 \\
\hline \multicolumn{5}{|c|}{ Calendar year of starting dual RAL/DRV } \\
\hline Per more recent & $1.18(0.87,1.59)$ & 0.294 & $1.78(1.07,2.95)$ & 0.025 \\
\hline \multicolumn{5}{|l|}{ Age } \\
\hline Per 10 years older & $0.78(0.58,1.04)$ & 0.089 & $0.50(0.25,0.99)$ & 0.045 \\
\hline \multicolumn{5}{|l|}{ CD4 count nadir } \\
\hline Per 100 cells higher & $1.07(0.84,1.35)$ & 0.595 & $0.83(0.49,1.42)$ & 0.499 \\
\hline \multicolumn{5}{|l|}{ CD4 count at starting cART } \\
\hline Per 100 cells higher & $1.07(0.93,1.22)$ & 0.343 & $1.19(0.88,1.62)$ & 0.259 \\
\hline \multicolumn{5}{|l|}{ Viral load at starting cART } \\
\hline Per $\log 10$ copies/mL higher & $1.22(0.95,1.56)$ & 0.114 & $0.92(0.54,1.59)$ & 0.777 \\
\hline \multicolumn{5}{|l|}{ Time with VL $\leq 50$} \\
\hline Per 6 months longer & $0.97(0.89,1.06)$ & 0.543 & $0.89(0.75,1.05)$ & 0.165 \\
\hline \multicolumn{5}{|l|}{ Previously failed a PI } \\
\hline Yes vs. no & $1.65(0.62,4.36)$ & 0.316 & $52.57(3.55,779.0)$ & 0.004 \\
\hline
\end{tabular}

$I D U$ injection drug users, $R A L$ raltegravir, $D R V$ darunavir, $P I$ protease inhibitor

*Hepatitis C or Hepatitis B co-infection 
The univariable HR for virological failure was 2.95 (95\% CI 1.03-8.27, $p=0.04$ ).

Mean (SD) CD4 count were 471 (164) cells $/ \mathrm{mm}^{3}$ by 3 months, 518 (213) 6 months, 552 (194) 9 months, 533 (203) by 12 months and 599 (108) by 24 months.

With regards to tolerability, we did not find any significant modification of total cholesterol, high-density lipoproteins (HDL), triglycerides, eGFR and alanine transaminase (AST) levels over 24 months (Fig. 1).

\section{Discussion}

Current guidelines suggest the use of a combination of three antiretroviral drugs as initial therapy, including 2 NRTIs plus $1 \mathrm{PI} / \mathrm{r}, 1$ integrase inhibitor or 1 NNRTI [811]. However, taking into account the rising evidence of nucleoside analogues long-term toxicity, NRTI-sparing strategies are being used in clinical practice.

We showed that, in an unselected patient population, representative of the clinical practice setting in Italy, a dual therapy including DRV/r + RAL seems to be moderately effective and tolerated over an average follow-up of 2 years. We found a relatively low probability of VF (considering both confirmed VL $>50$ or single value of $\mathrm{VL}>200$ copies $/ \mathrm{mL}$ ) ranging between 9 and $15 \%$ by 24 months from the time of switch. When we compared our results with those of the study by Calza et al. in a similar patient population we found higher rates of pure virological failure at 48 weeks ( 7 vs $2.4 \%$ ). However, it should be considered that in the study by Calza et al. patients with previous failure to PI containing regimens were excluded thus probably explaining the observed difference [15].

When considering the composite outcome of TF we observed a probability of 13 and $22 \%$ of failure at 12 and 24 months for the conservative definition of a single value of VL >200 copies/mL and stop/intensification. This result is in line with previous observational data on triple therapy in the observational cohort studies [17, 18].

Female gender and older age were independently associated with significantly lower risk of TF. It is possible that at least older age could represent a marker of better adherence $[19,20]$.

Contrary to what was found in PI/r monotherapy studies $[21,22]$, we did not find an increased risk of TF in

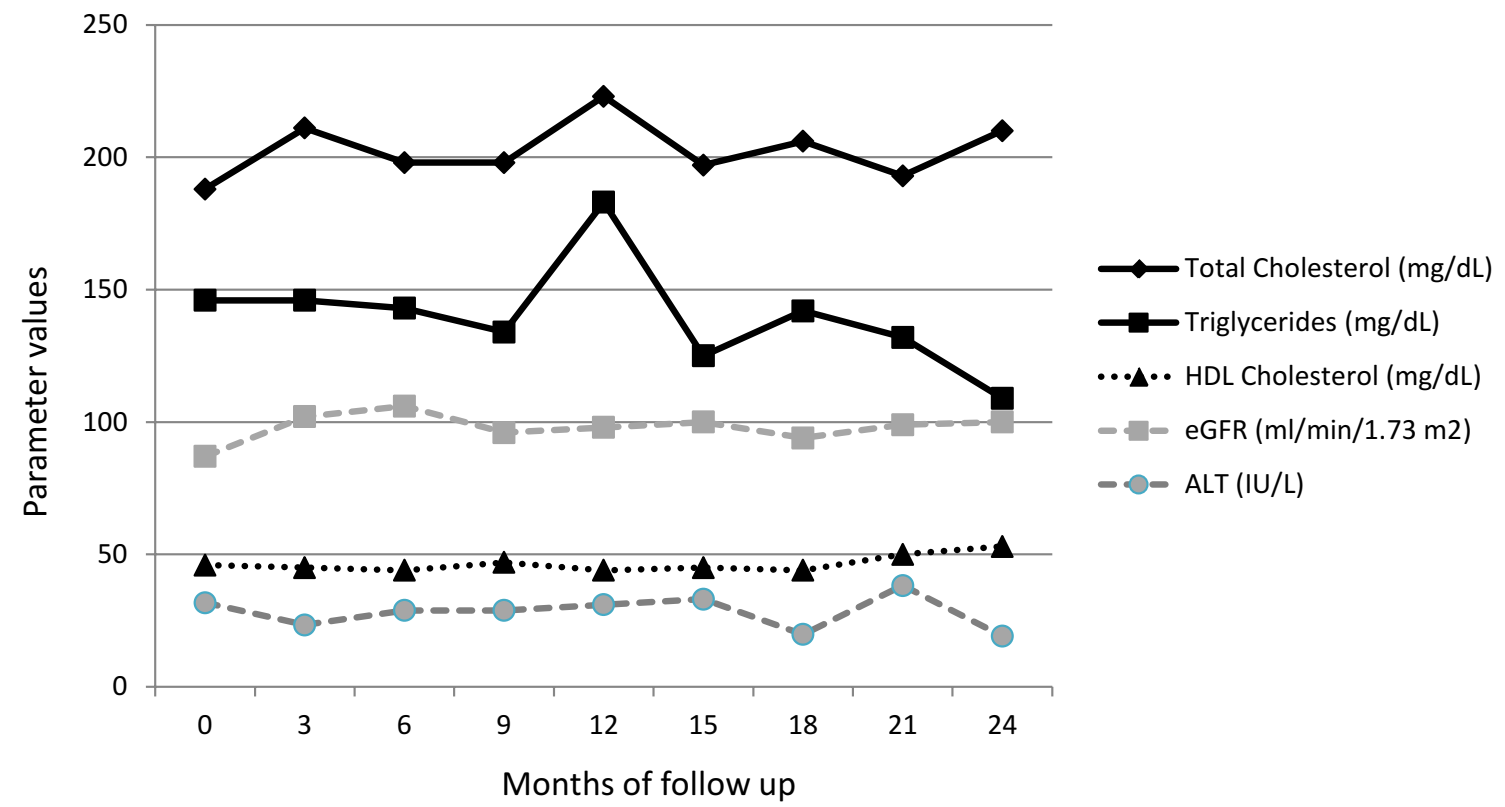

\begin{tabular}{|l|c|c|c|c|c|c|c|c|c|}
\hline \multicolumn{10}{|c|}{ Number of patients at each time point during follow up } \\
\hline Months & $\mathbf{0}$ & $\mathbf{3}$ & $\mathbf{6}$ & $\mathbf{9}$ & $\mathbf{1 2}$ & $\mathbf{1 5}$ & $\mathbf{1 8}$ & $\mathbf{2 1}$ & $\mathbf{2 4}$ \\
\hline Triglycerides & 70 & 18 & 10 & 18 & 14 & 17 & 9 & 10 & 12 \\
\hline HDL Cholesterol & 68 & 18 & 10 & 18 & 14 & 17 & 9 & 10 & 12 \\
\hline eGFR & 71 & 20 & 10 & 18 & 14 & 18 & 10 & 10 & 12 \\
\hline Total Cholesterol & 70 & 18 & 10 & 18 & 14 & 17 & 9 & 10 & 12 \\
\hline ALT & 72 & 20 & 10 & 18 & 14 & 18 & 9 & 10 & 12 \\
\hline
\end{tabular}

Fig. 1 Laboratory markers during follow-up (mean values at various time points from the date of switching to dual). $H D L$ high-density lipoproteins (mg/dL), eGFR estimated glomerular filtration rate (CKD-EPI formula), ALT alanine transferase (UI/L) 
patients with shorter duration of viral suppression, low nadir CD4 and with hepatic co-infections, suggesting that $\mathrm{DRV} / \mathrm{r}+\mathrm{RAL}$ might be used safely by a larger proportion of individuals. Having previously failed a PI-based regimen was strongly associated with TF. Furthermore, we showed that the presence of major IAS PI resistance was associated with an increased HR of virological failure, especially when considering a confirmed VL $>50$ copies $/ \mathrm{mL}$. Therefore, a previous failure of a PI-based regimen, especially if major IAS PI resistance mutations are detected, should remain a main limiting factor when selecting people for this strategy.

Our results also suggest that RAL + DRV/r is generally safe with a probability of discontinuation due to adverse events of $10 \%$ by 2 years.

We showed no significant modification in lipid profile whereas Calza et al. evidenced a significant reduction in triglyceride levels after 48 weeks [15]. However, in that study, baseline mean triglyceride values were above the normal range $(286 \mathrm{mg} / \mathrm{dL})$ compared to our patients that showed a median of 106 (IQR 75-156) mg/dl. Since our patients started from normal levels no further benefit was expected and our data suggest that the combination of DRV + RAL was not associated with a worsening in lipid profile.

Our results also showed a non-significant modification of eGFR during 24 months of follow-up as also suggested by Calza et al. and highlight the renal tolerability of the combination [15].

Our data also showed a trend to increase in CD4 cell count over time which is in line with the significant increase shown by Calza et al. at 48 weeks [15]. However, since only a few patients had available data at each followup time, we think it is fair to say that bigger studies are needed to confirm this result.

Most regimen discontinuations were due to treatment simplification $(15,50 \%)$ and twice daily RAL was the drug stopped probably due to the fear of selected nonadherence to one of the two daily doses. However, only a minority of discontinuations was due to virological failure $(1,3 \%)$ and toxicity $(3,10 \%)$ over 2 years. Adherence is a complex phenomenon that implies acceptance of the diagnosis and motivation to carry out the treatment, possession of appropriate skills and the ability to overcome any difficulties that appear to maintain the level of treatment success over time. In patients with multiple previous cART regimen tolerability may favor adherence more than the daily schedule. Although once daily dose is the goal to improve adherence, it is not always superior to twice daily dosing in terms of virologic success. In fact Nachega et al. evidenced that once daily therapy is associated with better adherence but not with better virologic results in a systematic review of 19 clinical trials [23]. Another recent study by Arroyo et al. found no difference in adherence rates in patients receiving once or twice daily regimens [24]. A French study showed that nonadherence was independently associated with side effects, and having a three times or more daily dosing regimen in comparison to once or twice daily therapy [25].

The upcoming availability of $1200 \mathrm{mg}$ once daily RAL and the present possibility to use co-formulated DRV/Cobicistat could represent a future advantage of the combination of DRV + RAL in virologically suppressed patients.

The main limitation of our analysis is the lack of a control group to compare the failure estimates of the dual $\mathrm{DRV} / \mathrm{r}+\mathrm{RAL}$ regimen to that of a standard triple cART. In particular, it is not obvious to set a threshold below which the proportion of failure of this strategy is too high to be acceptable (compared to remaining on triple regimens for example). In this case even the historical controls are not fully comparable as performed in the context of first-line cART. Furthermore, since only a half of the patients were switched from NRTI-including cART to $\mathrm{DRV} / \mathrm{r}+\mathrm{RAL}$, this study cannot evaluate the potential advantages of switching from a NRTI-including to a dual NRTI-sparing regimen.

In conclusion, switching to DRV/r + RAL in clinical practice is a valuable NRTI-sparing regimen, with a relative low risk of VF (7-9\%) and good tolerability after 2 years since start in an antiretroviral-experienced population. Of note, female and older patients, both vulnerable populations, seem to have greater benefits from this strategy. Larger studies are needed to establish more solid criteria for selecting people who might benefit from this dual regimen but previous failure of a PI-based ART should represent a limiting factor for this strategy.

\section{Acknowledgements Icona Foundation Study Group}

Board of directors A d'Arminio Monforte (Vice-President), M Andreoni, G Angarano, A Antinori, F Castelli, R Cauda, G Di Perri, M Galli, R Iardino, G Ippolito, A Lazzarin, CF Perno, F von Schloesser, P Viale.

Scientific secretary A d'Arminio Monforte, A Antinori, A Castagna, F Ceccherini-Silberstein, A Cozzi-Lepri, E Girardi, S Lo Caputo, C Mussini, M Puoti.

Steering committee M Andreoni, A Ammassari, A Antinori, C Balotta, A Bandera, P Bonfanti, S Bonora, M Borderi, A Calcagno, L Calza, MR Capobianchi, A Castagna, F Ceccherini-Silberstein, A Cingolani, P Cinque, A Cozzi-Lepri, A d'Arminio Monforte, A De Luca, A Di Biagio, E Girardi, N Gianotti, A Gori, G Guaraldi, G Lapadula, M Lichtner, S Lo Caputo, G Madeddu, F Maggiolo, G Marchetti, S Marcotullio, L Monno, C Mussini, S Nozza, M Puoti, E Quiros Roldan, R Rossotti, S Rusconi, MM Santoro, A Saracino, M Zaccarelli.

Statistical and monitoring team A Cozzi-Lepri, I Fanti, L Galli, P Lorenzini, A Rodano, M Shanyinde, A Tavelli. 
Biological bank INMI F Carletti, S Carrara, A Di Caro, S Graziano, F Petrone, G Prota, S Quartu, S Truffa.

Participating physicians and centers (Italy) A Giacometti, A Costantini, C Valeriani (Ancona); G Angarano, L Monno, C Santoro (Bari); F Maggiolo, C Suardi (Bergamo); P Viale, V Donati, G Verucchi (Bologna); F Castelli, E Quiros Roldan, C Minardi (Brescia); T Quirino, C Abeli (Busto Arsizio); PE Manconi, P Piano (Cagliari); B Cacopardo, B Celesia (Catania); J Vecchiet, K Falasca (Chieti); L Sighinolfi, D Segala (Ferrara); F Mazzotta, F Vichi (Firenze); G Cassola, C Viscoli, A Alessandrini, N Bobbio, G Mazzarello (Genova); C Mastroianni, V Belvisi (Latina); P Bonfanti, I Caramma (Lecco); A Chiodera, AP Castelli (Macerata); M Galli, A Lazzarin, G Rizzardini, M Puoti, A d'Arminio Monforte, AL Ridolfo, R Piolini, A Castagna, S Salpietro, L Carenzi, MC Moioli, C Tincati, G Marchetti (Milano); C Mussini, C Puzzolante (Modena); A Gori, G Lapadula (Monza); N Abrescia, A Chirianni, G Borgia, F Di Martino, L Maddaloni, I Gentile, R Orlando (Napoli); A Cascio, C Colomba (Palermo); F Baldelli, D Francisci (Perugia); G Parruti, T Ursini (Pescara); G Magnani, MA Ursitti (Reggio Emilia); R Cauda, M Andreoni, A Antinori, V Vullo, A Cristaudo, A Cingolani, G Baldin, S Cicalini, L Gallo, E Nicastri, R Acinapura, M Capozzi, R Libertone, S Savinelli, A Latini, G Iaiani, L Fontanelli Sulekova (Roma); M Cecchetto, F Viviani (Rovigo); MS Mura, G Madeddu (Sassari); A De Luca, B Rossetti (Siena); P Caramello, G Di Perri, GC Orofino, S Bonora, M Sciandra (Torino); M Bassetti, A Londero (Udine); G Pellizzer, V Manfrin (Vicenza).

\begin{abstract}
Authors' contributions GM, SR, ACL, ADB and AA contributed to study conception and design, analysis and interpretation of the data and drafting of the article; SDG, SB, ADL, AC and NG contributed to the analysis and interpretation of data and to the critical revision of the manuscript for important intellectual content; all authors gave final approval of the final manuscript.
\end{abstract}

\section{Compliance with ethical standards}

Ethics approval and consent to participate All patients enrolled gave written, informed consent to participation in the ICONA Foundation cohort study and the study was approved by each of the Ethics Committees from the sites participating to the ICONA Foundation Study.

Conflict of interests GM has been advisor for Gilead Sciences, Janssen and Merck Sharp and Dohme and ViiV Healthcare and has received speakers' honoraria from Bristol-Myers Squibb, Gilead Sciences, Merck Sharp and Dohme, Janssen and ViiV Healthcare; SR has received research grants from Gilead Sciences, Janssen, ViiV Healthcare and consultancy honoraria and speaking fees from Abbvie, Bristol-Myers Squibb, Gilead Sciences, Merck Sharp \& Dohme, Janssen and ViiV Healthcare; ACL declares non conflict of interest; SDG received speaker's honoraria from Bristol Myers Squibb, Janssen, Merck Sharp \& Dohme and ViiV Healthcare; SB has received speaker's honoraria, travel grants or advisory board honoraria from Abbvie, Bristol-Myers Squibb, Gilead Sciences, Janssen, Merck Sharp \& Dohme and ViiV Healthcare, AC declares no conflict of interest; ADL received research grants from Gilead Sciences, Merck Sharp and Dohme, ViiV Healthcare and consultant fees from AbbVie, BristolMyers Squibb, Gilead, Merck Sharp and Dohme, ViiV Healthcare and Janssen; NG has been advisor for Abbvie, Gilead Sciences, and Janssen and has received speakers' honoraria from AbbVie, Boehringer Ingelheim, Bristol-Myers Squibb, Gilead Sciences, Merck Sharp and Dohme, Roche, ViiV Healthcare and Janssen; ADB has been advisor for AbbVie, Gilead Sciences and Merck Sharp and Dohme and has received speakers' honoraria from Bristol-Myers Squibb, Gilead Sci- ences, Merck Sharp and Dohme, Janssen and ViiV Healthcare; AA has received speaker's fees or travel grants from Abbvie, Bristol-Myers Squibb, Gilead Sciences, Janssen, Merck Sharp \& Dohme and ViiV Healthcare and research grants from Bristol-Myers Squibb.

Funding The authors received no specific funding for this work. However, the ICONA Foundation is sponsored by unrestricted educational grants from Bristol-Myers Squibb, Gilead Sciences, Jannsen, Merck Sharp and Dohme, ViiV, Italy. The funders had no role in study design, data collection and analysis, decision to publish, or preparation of the manuscript.

\section{References}

1. Maagard A, Kvale D. Mitochondrial toxicity in HIV-infected patients both off and on antiretroviral treatment: a continuum or distinct underlying mechanisms? J Antimicrob Chemother. 2009;64:901-9.

2. Gerschenson M, Brinkman K. Mitochondrial dysfunction in AIDS and its treatment. Mitochondrion. 2004;4:763-77.

3. Blas-García A, Martí-Rodrigo A, Víctor VM, Polo M, Alegre F, Funes HA, Apostolova N, Esplugues JV. The purine analogues abacavir and didanosine increase acetaminophen-induced hepatotoxicity by enhancing mitochondrial dysfunction. J Antimicrob Chemother. 2016;71:916-26.

4. Negredo E, Miró O, Rodríguez-Santiago B, Garrabou G, Estany C, Masabeu A, Force L, Barrufet P, Cucurull J, Domingo P, Alonso-Villaverde C, Bonjoch A, Morén C, Pérez-Alvarez N, Clotet B, MULTINEKA Study Group. Improvement of mitochondrial toxicity in patients receiving a nucleoside reverse-transcriptase inhibitor-sparing strategy: results from the Multicenter Study with Nevirapine and Kaletra (MULTINEKA). Clin Infect Dis. 2009;49:892-900.

5. Di Giambenedetto S, Fabbiani M, Colafigli M, Ciccarelli N, Farina S, Sidella L, D'Avino A, Mondi A, Cingolani A, Tamburrini E, Murri R, Navarra P, Cauda R, De Luca A. Safety and feasibility of treatment simplification to atazanavir/ritonavir + lamivudine in HIV-infected patients on stable treatment with two nucleos $(\mathrm{t})$ ide reverse transcriptase inhibitors + atazanavir/ritonavir with virological suppression (Atazanavir and Lamivudine for treatment Simplification, AtLaS pilot study). J Antimicrob Chemother. 2013;68:1364-72.

6. Mondi A, Fabbiani M, Ciccarelli N, Colafigli M, D'Avino A, Borghetti A, Gagliardini R, Cauda R, De Luca A, Di Giambenedetto $\mathrm{S}$. Efficacy and safety of treatment simplification to atazanavir/ritonavir + lamivudine in HIV-infected patients with virological suppression: 144 week follow-up of the AtLaS pilot study. J Antimicrob Chemother. 2015;70:1843-9.

7. Llibre JM, Alvarez H, Antela A, Toro J, Payeras A, Pérez-Elías MJ, Imaz A, Masià M, Pérez-Alvarez N, Burgos J, Clotet B, Members of the Nuke-Out Study. Withdrawing inactive NRTIs in HIV-1 subjects with suppressed viraemia: a randomized trial. J Antimicrob Chemother. 2016;71:1346-51.

8. Guidelines for the Use of Antiretroviral Agents in HIV-1-Infected Adults and Adolescents. http://aidsinfo.nih.gov/guidelines. Accessed 28 Jan 2016.

9. Thompson MA, Aberg JA, Hoy JF, Telenti A, Benson C, Cahn P, Eron JJ, Günthard HF, Hammer SM, Reiss P, Richman DD, Rizzardini G, Thomas DL, Jacobsen DM, Volberding PA. Antiretroviral treatment of adult HIV infection: 2012 recommendations of the International Antiviral Society-USA panel. JAMA. 2012;308:387-402. 
10. European AIDS Clinical Society. HIV Guidelines version 8.0 October 2015. http://www.eacsociety.org/files/2015_ eacsguidelines_8_0-english_rev-20160124.pdf.

11. Ministero della Salute e Società Italiana di Malattie Infettive. Linee Guida Italiane sull'utilizzo dei farmaci antiretrovirali e sulla gestione diagnostico-clinica delle persone con infezione da HIV-1. http://www.salute.gov.it/imgs/C_17_pubblicazioni_2442_allegato.pdf. Accessed $24 \mathrm{Feb} 2016$.

12. Imaz A, Llibre JM, Mora M, Mateo G, Camacho A, Blanco JR, Curran A, Santos JR, Caballero E, Bravo I, Gayá F, Domingo P, Rivero A, Falcó V, Clotet B, Ribera E. Efficacy and safety of nucleoside reverse transcriptase inhibitor-sparing salvage therapy for multidrug-resistant HIV-1 infection based on new-class and new-generation antiretrovirals. J Antimicrob Chemother. 2011;66:358-62.

13. Sterrantino G, Zaccarelli M, Di Biagio A, Biondi ML, Antinori A, Penco G, ARCA Study Group. Darunavir-based dual therapy of treatment-experienced HIV-infected patients: analysis from a national multicenter database. Infection. 2015;43:339-43.

14. Di Biagio A, Ricci E, Viscoli C, Mesini A, Menzaghi B, Carenzi L, Orofino G, Parruti G, Martinelli C, Madeddu G, De Socio GV, Franzetti M, Quirino T, Bonfanti P, CISAI Group. The use of nucleoside reverse transcriptase inhibitors sparing regimens in treatment-experienced HIV-1 infected patients. Curr HIV Res. 2013;11:179-86.

15. Calza L, Danese I, Magistrelli E, Colangeli V, Manfredi R, Bon I, Re MC, Conti M, Viale P. Dual raltegravir-darunavir/ritonavir combination in virologically suppressed HIV-1-infected patients on antiretroviral therapy including a ritonavir-boosted protease inhibitor plus two nucleoside/nucleotide reverse transcriptase inhibitors. HIV Clin Trials. 2016;17:38-47.

16. Inker LA, Schmid CH, Tighiouart H, Eckfeldt JH, Feldman HI, Greene T, Kusek JW, Manzi J, Van Lente F, Zhang YL, Coresh J, Levey AS, CKD-EPI Investigators. Estimating glomerular filtration rate from serum creatinine and cystatin C. New Eng J Med. 2012;367:20-9.

17. Cicconi P, Cozzi-Lepri A, Castagna A, Trecarichi EM, Antinori A, Gatti F, Cassola G, Sighinolfi L, Castelli P, d'Arminio Monforte A, ICoNA Foundation Study Group. Insights into reasons for discontinuation according to year of starting first regimen of highly active antiretroviral therapy in a cohort of antiretroviralnaïve patients. HIV Med. 2010;11:104-13.

18. Di Biagio A, Cozzi-Lepri A, Prinapori R, Angarano G, Gori A, Quirino T, De Luca A, Costantini A, Mussini C, Rizzardini G, Castagna A, Antinori A, d'Arminio Monforte A, ICONA
Foundation Study Group. Discontinuation of initial antiretroviral therapy in clinical practice: moving toward individualized therapy. J Acquir Immune Defic Syndr. 2016;71:263-71.

19. Viswanathan S, Detels R, Mehta SH, Macatangay BJ, Kirk GD, Jacobson LP. Level of adherence and HIV RNA suppression in the current era of highly active antiretroviral therapy (HAART). AIDS Behav. 2015;19:601-11.

20. Trotta MP, Ammassari A, Cozzi-Lepri A, Zaccarelli M, Castelli F, Narciso P, Melzi S, De Luca A, Monforte AD, Antinori A, Adherence Italian Cohort Naive Antiretrovirals (AdICONA) Study Group, Adherence Spallanzani (AdeSpall) Study, Cicconi P, Cozzi-Lepri A, Castagna A, Trecarichi EM, Antinori A, Gatti F, Cassola G, Sighinolfi L, Castelli P, d'Arminio Monforte A, ICoNA Foundation Study Group. Insights into reasons for discontinuation according to year of starting first regimen of highly active antiretroviral therapy in a cohort of antiretroviral-naïve patients. HIV Med. 2010;11:104-13.

21. Clumeck N, Rieger A, Banhegyi D, Schmidt W, Hill A, Van Delft Y, Moecklinghoff C, Arribas J. 96 week results from the MONET trial: a randomized comparison of darunavir/ritonavir with versus without nucleoside analogues, for patients with HIV RNA $<50$ copies/mL at baseline. J Antimicrob Chemother. 2011;66:1878-85.

22. Curran A, Monteiro P, Domingo P, Villar J, Imaz A, Martínez E, Fernández I, Knobel H, Podzamczer D, Iribarren JA, Peñaranda M, Crespo M, PIMOCS Study Group. Effectiveness of ritonavirboosted protease inhibitor monotherapy in the clinical setting: same results as in clinical trials? The PIMOCS Study Group. J Antimicrob Chemother. 2014;69:1390-6.

23. Nachega JB, Parienti JJ, Uthman OA, Gross R, Dowdy DW, Sax PE, Gallant JE, Mugavero MJ, Mills EJ, Giordano TP. Lower pill burden and once-daily antiretroviral treatment regimens for HIV infection: a meta-analysis of randomized controlled trials. Clin Infect Dis. 2014;58:1297-307.

24. Hernández Arroyo MJ, Cabrera Figueroa SE, Sepúlveda Correa R, Valverde Merino MP, Luna Rodrigo G, Domínguez-Gil Hurlé A, Tormes Team. Influence of the number of daily pills and doses on adherence to antiretroviral treatment: a 7-year study. J Clin Pharm Ther. 2016;41:34-9.

25. Protopopescu C, Raffi F, Roux P, Reynes J, Dellamonica P, Spire B, Leport C, Carrieri MP, ANRS CO8 APROCO-COPILOTE Study Group. Factors associated with non-adherence to longterm highly active antiretroviral therapy: a 10 year follow-up analysis with correction for the bias induced by missing data. J Antimicrob Chemother. 2009;64:599-606. 